\title{
On-line gas-phase separation of short-lived bromine nuclides from precursor selenium
}

\author{
By M. Wachsmuth ${ }^{\dagger}$, B. Eichler, L. Tobler, D. T. Jost, H. W. Gäggeler ${ }^{\dagger}$ and M. Ammann* \\ Paul Scherrer Institut, CH-5232 Villigen, Switzerland
}

(Received April 18, 2000; accepted in revised form June 30, 2000)

Gas-phase separation / Short-lived bromine nuclides / Selenium / Carbonyl selenide (OCSe) / Labelled bromine / Spallation neutron source

Summary. Short-lived bromine nuclides, available from thermal neutron induced nuclear fission of ${ }^{235} U$, may be useful tracers for laboratory studies in atmospheric chemistry. Shortlived fission products were delivered continuously to a laboratory with the gas-jet facility at the spallation neutron source SINQ. To increase the selectivity for the fission products from the light mass peak, the ${ }^{235} \mathrm{U}$ target was covered with a nickel foil to suppress the heavy fission products having lower recoil energies. In addition, carbon monoxide $(\mathrm{CO})$ or propene $\left(\mathrm{C}_{3} \mathrm{H}_{6}\right)$ were added as reactive gases to the He carrier gas rather than aerosol particles. Besides isotopes from the noble gas krypton and its descendants, a selective transport of selenium isotopes was observed with each of these gases, though with higher yield using $\mathrm{CO} / \mathrm{He}$. Through $\beta^{-}$-decay bromine isotopes are formed from selenium precursors. A bromine generator was established through controlled decomposition of the transported carbonyl selenide $\left(\mathrm{OC}^{83-87} \mathrm{Se}\right)$ and adsorption of the resulting elemental selenium on quartz. The addition of carrier bromine to the carrier gas led to a complete mobilisation of the bromine nuclides from the quartz surface while retaining selenium. With this procedure, a source of gaseous bromine species, presumably in the form of $\mathrm{Br}_{2}$ with the isotopes ${ }^{83-87} \mathrm{Br}$, could be established.

\section{Introduction}

Bromine containing compounds are known to play an important role in the ozone chemistry in various regions of the atmosphere [1]. Barrie et al. [2] first reported a relationship between spring-time ozone destruction in the lower Arctic troposphere which showed a strong negative correlation between the concentrations of ozone and bromine compounds. There is also increasing evidence that similar processes affect the ozone budget in Antarctica [3], at mid-latitudes [4] and in the subtropics [5]. In particular, the mechanisms describing the heterogeneous reactions of gas-phase bromine compounds on aerosol surfaces typically found in the atmosphere such as sea-salt particles, are not entirely understood. The investigation of heterogeneous chemistry

\footnotetext{
† Also at Department of Chemistry and Biochemistry, University of Bern, Bern, Switzerland.

* Author for correspondence (E-mail: markus.ammann@psi.ch).
}

under simulated conditions in the laboratory is difficult, as the atmosphere is a multiphase system with variable humidity and a complex gaseous environment. Especially for heterogeneous reactions, the use of short-lived radioactive tracers has proven to be a highly valuable tool because of its high sensitivity and capability for the in situ detection of surface bound species under real gas conditions. For aerosol experiments, ${ }^{13} \mathrm{~N}$ with a half-life of 10 minutes has already been successfully used for studies of heterogeneous reactions of nitrogen oxides on several particle surfaces such as soot [6].

The aim of this study was to establish a source of bromine nuclides to be used as tracers in similar experiments. At the Swiss Spallation Neutron Source (SINQ) at Paul Scherrer Institute, Switzerland, a gas-jet facility with ${ }^{235} \mathrm{U}$ targets has been installed. Using the gas-jet approach [7], thermal neutron induced fission products (e.g. bromine) can easily be transported to a chemistry laboratory through flexible tubes by attaching the nuclides to particles suspended in the gas flow passing the target. In order to increase the selectivity of the system for the more volatile fission products, the suspended particles can be omitted and, instead, a reactive gas be added to promote the exclusive transport of nuclides being able to form volatile and stable compounds. As will be shown below, the most promising approach for a source of bromine nuclides was to transport its precursor selenium and to separate the bromine daughter nuclides in an on-line gas chemistry system.

\section{Experimental}

The SINQ gas-jet facility is a versatile instrument for the production of short-lived fission products of ${ }^{235} \mathrm{U}$ [8]. Bromine isotopes with half-lives ranging from 55 seconds $\left({ }^{86} \mathrm{Br}\right)$ up to 2.4 hours $\left({ }^{83} \mathrm{Br}\right)$ are available in this way. The neutron flux on the targets can be adjusted by means of a mechanical shutter between $10^{7}$ and $10^{9}$ neutrons $\mathrm{cm}^{-2} \mathrm{~s}^{-1}$, leading to ${ }^{235} \mathrm{U}$ fission rates of $10^{4}$ to $10^{6} \mathrm{~s}^{-1}$. The product nuclei are stopped to thermal velocity in the corresponding target chamber, which is continuously purged by a gas. To meet the requirements of different experiments several chambers are available. They are optimised to different gas media (e.g. He or $\mathrm{N}_{2}$ ) as well as to different fission products (fission fragments from light mass peak only or all fission fragments). For the experiments described in the following, 


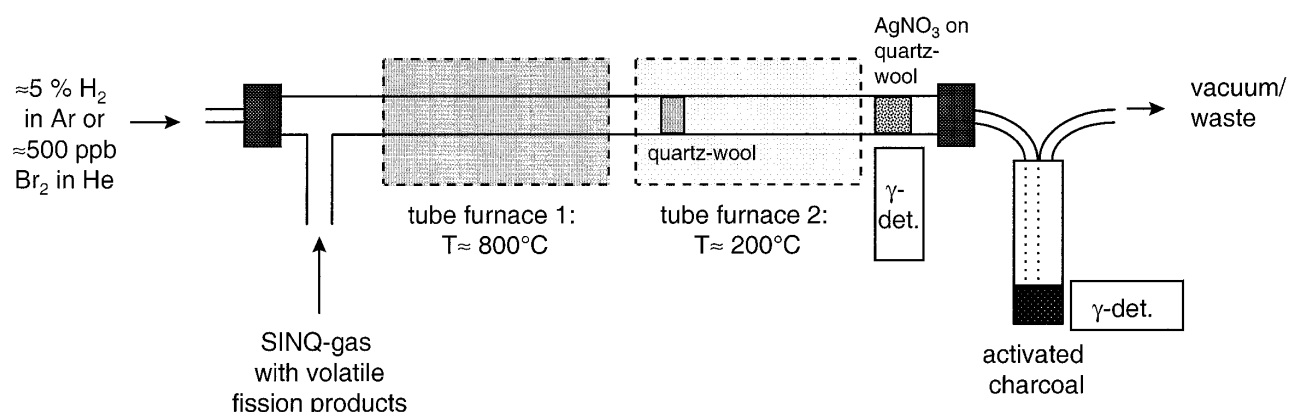

Fig. 1. Set-up of the on-line $\mathrm{Br}^{-84} \mathrm{Br}$ source. The gas returning from the fas-jet facility, containing volatile fission products, enters the quartz tube through a separate inlet. In a first tube furnace, the transport molecules with the fission products were decomposed and the resulting Se atoms were deposited on a clean quartz-wool plug in a second tube furnace. Bromine, the decay product, was mobilised by addition of $\mathrm{H}_{2}$ or $\mathrm{Br}_{2}$ and was detected on $\mathrm{AgNO}_{3}$ coated quartz-wool. The impermeability of the $\mathrm{AgNO}_{3}$ /quartz-wool for $\mathrm{Br}$ and $\mathrm{Se}$ was checked by a trap filled with activated charcoal, placed at the exit of the chemical apparatus.

a $25 \mathrm{~mm}$ chamber was used with a $6 \mu \mathrm{m}$ nickel degrading foil covering a $0.23 \mathrm{mg} / \mathrm{cm}^{2}{ }^{235} \mathrm{U}$ target suppressing the emission of fission fragments from the heavy mass peak [9]. The absolute pressure in the chamber was 1.82 bar. The inlet and outlet tubes, which connect the chamber with the outside of the insertion module, are made of anodised aluminium and have an inner diameter of 4 and $2 \mathrm{~mm}$, respectively. From there, several flexible tubes, different in material and diameter, are available for the transport to the laboratory. In this study, a polyethylene tube with an inner diameter of $4 \mathrm{~mm}$ was used. This tube was jacketed with an outer tube, purged by argon, in order to reduce impurities (e.g. $\mathrm{O}_{2}, \mathrm{H}_{2} \mathrm{O}$ ) caused by the permeability of the polyethylene. Through this transport line, nuclides produced in the target chamber are transported to the $80 \mathrm{~m}$ distant laboratory by a He gas flow $\left(11 \mathrm{~min}^{-1}, 99.9999 \%\right.$, Sauerstoffwerke Lenzburg). The transport time of the gas mixture from the target chamber back to the laboratory is around $7-10$ seconds for a gas-flow of $11 \mathrm{~min}^{-1}$. This is a limiting factor for the repertory of available isotopes. If the halflive of the selenium precursor is shorter or of the same magnitude, the resulting bromine isotopes are lost on the walls of the polyethylene tube if they do not form transportable molecules.

Among the large variety of fission products, only bromine nuclides were of interest. Hence, a suitable gas phase reactant, expected to form a stable bromine compound had to be added to the carrier gas to improve the selectivity for bromine already in the target chamber. In the target chamber, all nuclides are thought to occur in a radical state after thermalisation. Several compounds were of interest: methane could react with bromine to methyl-bromide as reported by Kratz et al. [10], but no useful transport efficiency was achieved. Ethene, the gas which is often added for halogen separation [11-14], was not used because of the risk of partial polymerisation [15] in the gas-jet chamber resulting in possible pollution problems. An alternative to ethene is $\mathrm{C}_{3} \mathrm{H}_{6}$, because no radical initiated polymerisation of this molecule is known, especially in the absence of catalysts [15]. CO, which has a high electron density between the carbon and oxygen atom, is able to build a van der Waals interaction with atoms like bromine (electronic configuration $[\mathrm{Ar}] 3 \mathrm{~d}^{10} 4 \mathrm{~s}^{2} 4 \mathrm{p}^{5}$ ) lacking a valence electron. Finally, $\mathrm{CO}$ and $\mathrm{C}_{3} \mathrm{H}_{6}$ were used for all further experiments.
$\mathrm{CO}$ and $\mathrm{C}_{3} \mathrm{H}_{6}$, each $1 \%$ in helium (Carbagas) were diluted to achieve concentrations ranging from 600 to $768 \mathrm{ppm}$ and added as reactive gases.

The closed gas flow system consisted of two tube furnaces, which could be heated each up to $900^{\circ} \mathrm{C}$ and of a quartz-column equipped with separate inlets (Fig. 1). Through these inlets, the gas exiting the gas-jet facility and, if needed, hydrogen (7\% in Ar, Sauerstoffwerke Lenzburg) or bromine (Fluka puriss. p.a. 16040) entered the system. On a quartz-wool plug placed several centimetres inside the second tube furnace, the combustion products from the first tube furnace were deposited. Nuclides passing the second tube furnace were collected on the following trapping materials kept at temperatures between $25^{\circ} \mathrm{C}$ and $\leq 200^{\circ} \mathrm{C}$ : pure quartz-wool, silver coated glass globules, silver granules (Aldrich 99.99\%, +60 mesh, 30337-2), silver nitrate (Fluka puriss. p.a. 85228) on quartz-wool or activated charcoal (Merck, 0.5-1 mm, 109246). The silver coated glass globules were made of $\mathrm{AgNO}_{3}$ (Fluka puriss. p.a. 85228) deposited on the glass surface and decomposed to elemental silver at $500^{\circ} \mathrm{C}$ in an inert gas flow. The activity in the traps was analysed by $\gamma$-spectroscopy using a portable and calibrated HPGe detector. Care was taken to position the detector such that all measurements were performed in a comparable geometric configuration. A second trap, filled with activated charcoal, was installed either to check for breakthrough of the nuclide of interest in the first one or to detect the fission noble gases, for reference. All relevant tubes and connectors were made of Teflon. The total gas flow in the system depending on the actual experiment ranged from $1100-1300 \mathrm{ml} \mathrm{min}^{-1}$ and was composed of $1000 \mathrm{ml} \mathrm{min}^{-1}$ of helium as carrier gas $(>99.9999 \%$,

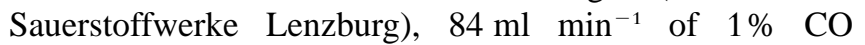
$(99.997 \%)$ or $1 \% \mathrm{C}_{3} \mathrm{H}_{6}(99.4 \%)$ in helium $(99.9990 \%)$ (carbagas), $200 \mathrm{ml} \mathrm{min}^{-1}$ of $7 \% \mathrm{H}_{2}(>99.993 \%)$ in $\mathrm{Ar}$ (>99.998\%) (Sauerstoffwerke Lenzburg) and $10 \mathrm{ml} \mathrm{min}^{-1}$ of helium $(99.9999 \%)$. The last gas flow was used to add carrier bromine to the system from a small bottle containing bromine (Fluka puriss. p.a. 16040). It was immersed in a coolant at $-75^{\circ} \mathrm{C}$ in order to provide a low $\mathrm{Br}_{2}$ partial pressure $(\leq 8 \mathrm{~Pa})$. The gas leaving the system was pumped to waste by a diaphragm pump (KNF) and the total pressure was regulated to $90 \mathrm{kPa}$. 
Table 1. Comparison of resulting activty of ${ }^{84} \mathrm{Se}$ and ${ }^{84} \mathrm{Br}$ under different transport conditions (wihtout or with reactive gas) and with different reaction conditions (mobilisation of bromine with use of $\mathrm{H}_{2} \mathrm{or} \mathrm{Br}_{2}$ ).

\begin{tabular}{lcc}
\hline Conditions & $\begin{array}{l}\text { Activity } \\
\text { of }{ }^{84} \mathrm{Se}[\mathrm{Bq}]\end{array}$ & $\begin{array}{l}\text { Activity } \\
\text { of }{ }^{84} \mathrm{Br}[\mathrm{Bq}]\end{array}$ \\
\hline Pure helium & 139 & 66 \\
$600 \mathrm{ppm} \mathrm{CO}$ in $\mathrm{He}$ & 1060 & 1308 \\
$600 \mathrm{ppm} \mathrm{CO}, 3,3 \%$ o $\mathrm{H}_{2}$ in $\mathrm{He}$ & 34 & 230 \\
$768 \mathrm{ppm} \mathrm{CO}, 914 \mathrm{ppb} \mathrm{Br}_{2}$ in $\mathrm{He}$ & not detectable & 2238 \\
\hline
\end{tabular}

\section{Results and discussion}

\section{Direct catch experiments}

The transport characteristics of the gas-jet system were studied by bypassing the gas-chemistry set-up and directly collecting the products on activated charcoal or $\mathrm{AgNO}_{3}$ coated quartz-wool. The latter filling had a better signalto-noise ratio in the $\gamma$-spectra, presumably due to reduced retention times of noble gas nuclides in the trap. With pure helium as carrier gas only little $\mathrm{Se}$ and $\mathrm{Br}$ were transported (Table $1 ; 1^{\text {st }}$ line.

Surprisingly, for both reactive gases added, $\mathrm{CO}$ and $\mathrm{C}_{3} \mathrm{H}_{6}$, mainly Se nuclides were transported to the laboratory. Fig. 2 shows that the $\mathrm{Br}$ activity observed in the trap originated exclusively from decay of Se rather than from transport of $\mathrm{Br}$ species. The most likely molecule originating from the reaction of selenium atoms with $\mathrm{CO}$ is carbonyl selenide [16], and for $\mathrm{C}_{3} \mathrm{H}_{6}$ it is probably propaneselenal, a $\mathrm{C}_{3}$ seleno-aldehyde with a double bond between the terminal carbon atom and the selenium [17]. Moreover, in the presence of traces of hydrogen in the carrier gas, a reaction to labelled hydrogen bromide might occur, but $\mathrm{HBr}$ reacts strongly with the surface of the $70 \mathrm{~m}$ transport capillary, especially the metallic surfaces close to the target. This could be a second reason for the poor bromine yield.

The saturation count-rates of ${ }^{84} \mathrm{Se}$ were measured in the trap as $10.6 \mathrm{cps}$ at $600 \mathrm{ppm} \mathrm{CO}$ in a heated quartz tube $\left(\approx 200^{\circ} \mathrm{C}\right.$ ) filled with $\mathrm{AgNO}_{3}$ coated quartz-wool (Table 1;

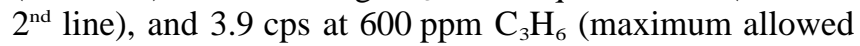
concentration) in a quartz tube filled with clean quartz-wool at room temperature. These trapping materials were quite specific for the products, i.e., the products transported with $\mathrm{C}_{3} \mathrm{H}_{6}$ were not retained in the trap used for the products with $\mathrm{CO}$, and vice versa. Because of the higher yield, only $\mathrm{CO}$ was used for further experiments. A typical $\gamma$-spectrum under such conditions is shown in Fig. 3 and the measured activities are listed in Table 2 [18].

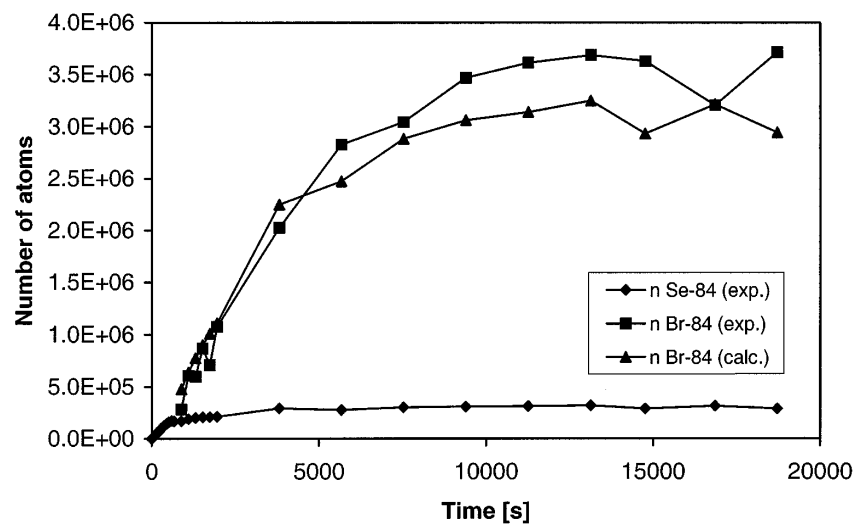

Fig. 2. Number of $\mathrm{Br}$ and $\mathrm{Se}$ atoms measured in an activated charcoal trap at the end of the gas-jet, compared to the number of $\mathrm{Br}$ atoms calculated from the decay of the measured Se atoms. Obviously, the entire Br activity is caused by the decay of precursor Se and not by direct formation. Note the shorter half-life of ${ }^{84} \mathrm{Se}(3.1 \mathrm{~min})$ than ${ }^{84} \mathrm{Br}$ (31.8 min) leading to a ten times higher number of daughter than parent atoms.

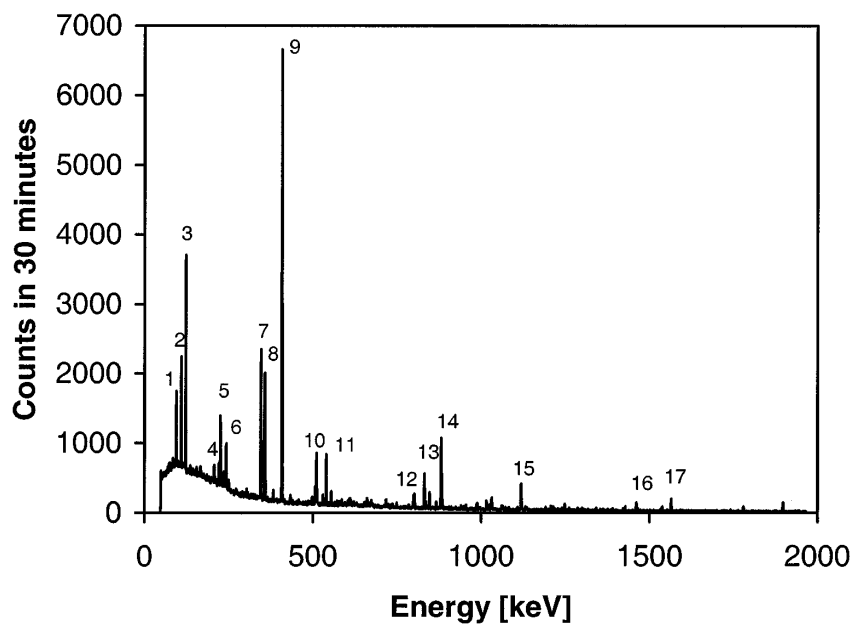

Fig. 3. $\gamma$-Spectrum measured during 30 minutes on $\mathrm{AgNO}_{3}$ coated quartz-wool at room temperature. Carbonyl-selenide (OCSe), the resulting transport molecules of the addition of CO $(600 \mathrm{ppm})$ was not decomposed at temperatures below $800^{\circ} \mathrm{C}$ and could be detected behind the second tube furnace. The marked peaks are: $1:{ }^{91} \mathrm{Rb} ; 2:{ }^{91} \mathrm{Kr}$; 3: ${ }^{90} \mathrm{Kr} ; 4:{ }^{86} \mathrm{Se} ; 5:{ }^{83} \mathrm{Se} ; 6:{ }^{90} \mathrm{Kr} ; 7:{ }^{91} \mathrm{Rb} ; 8:{ }^{83} \mathrm{Se} ; 9:{ }^{84} \mathrm{Se} ; 10:$ positron annihilation; $11:{ }^{90} \mathrm{Kr} ; 12:{ }^{83} \mathrm{Se},{ }^{85} \mathrm{Br},{ }^{84} \mathrm{Br} ; 13:{ }^{90} \mathrm{Rb} ; 14:{ }^{84} \mathrm{Br} ; 15$ : ${ }^{90} \mathrm{Kr} ; 16:{ }^{40} \mathrm{~K} ; 17:{ }^{86} \mathrm{Br}$.

Besides ${ }^{90,91} \mathrm{Kr}$ and its decay products ${ }^{90,91} \mathrm{Rb}$ and background ${ }^{40} \mathrm{~K}$, only lines from ${ }^{83,84,86} \mathrm{Se}$ and its decay products ${ }^{83-86} \mathrm{Br}$ are detected.
Table 2. List of all detected selenium and bromine nuclides in a typical experiment with $600 \mathrm{ppm} \mathrm{CO}$ added to the helium transport gas. All nuclides were caught on quartz-wool coated with $\mathrm{AgNO}_{3}$ [18].

\begin{tabular}{lccccl}
\hline Nuclide & $\begin{array}{l}\text { Half-life } \\
{[\mathrm{s}]}\end{array}$ & $\begin{array}{l}\gamma \text {-Energy } \\
{[\mathrm{keV}]}\end{array}$ & $\begin{array}{l}\text { Abundance } \\
{[\%]}\end{array}$ & $\begin{array}{l}\text { Activity } \\
{[\mathrm{Bq}](\mathrm{exp})}\end{array}$ & Remarks \\
\hline${ }^{83 \mathrm{Se}}$ & $22.3 \mathrm{~m}$ & 356.69 & 70 & 410 & \\
${ }^{84} \mathrm{Se}$ & $3.1 \mathrm{~m}$ & 408.2 & 100 & 1060 & \\
${ }^{85} \mathrm{Se}$ & $31.7 \mathrm{~s}$ & 1427.2 & 7.0 & 524 & \\
${ }^{86} \mathrm{Se}$ & $15.3 \mathrm{~s}$ & 207.5 & 7.8 & 261 & peak is covered by ${ }^{84} \mathrm{Br}$ \\
${ }^{83} \mathrm{Br}$ & $2.40 \mathrm{~h}$ & 529.66 & 1.2 & 3529 & \\
${ }^{84} \mathrm{Br}$ & $31.8 \mathrm{~m}$ & 881.61 & 42 & 1308 & none \\
${ }^{85} \mathrm{Br}$ & $2.90 \mathrm{~m}$ & 802.41 & 2.56 & 250 & \\
${ }^{86} \mathrm{Br}$ & $55.1 \mathrm{~s}$ & 1564.92 & 64 & &
\end{tabular}




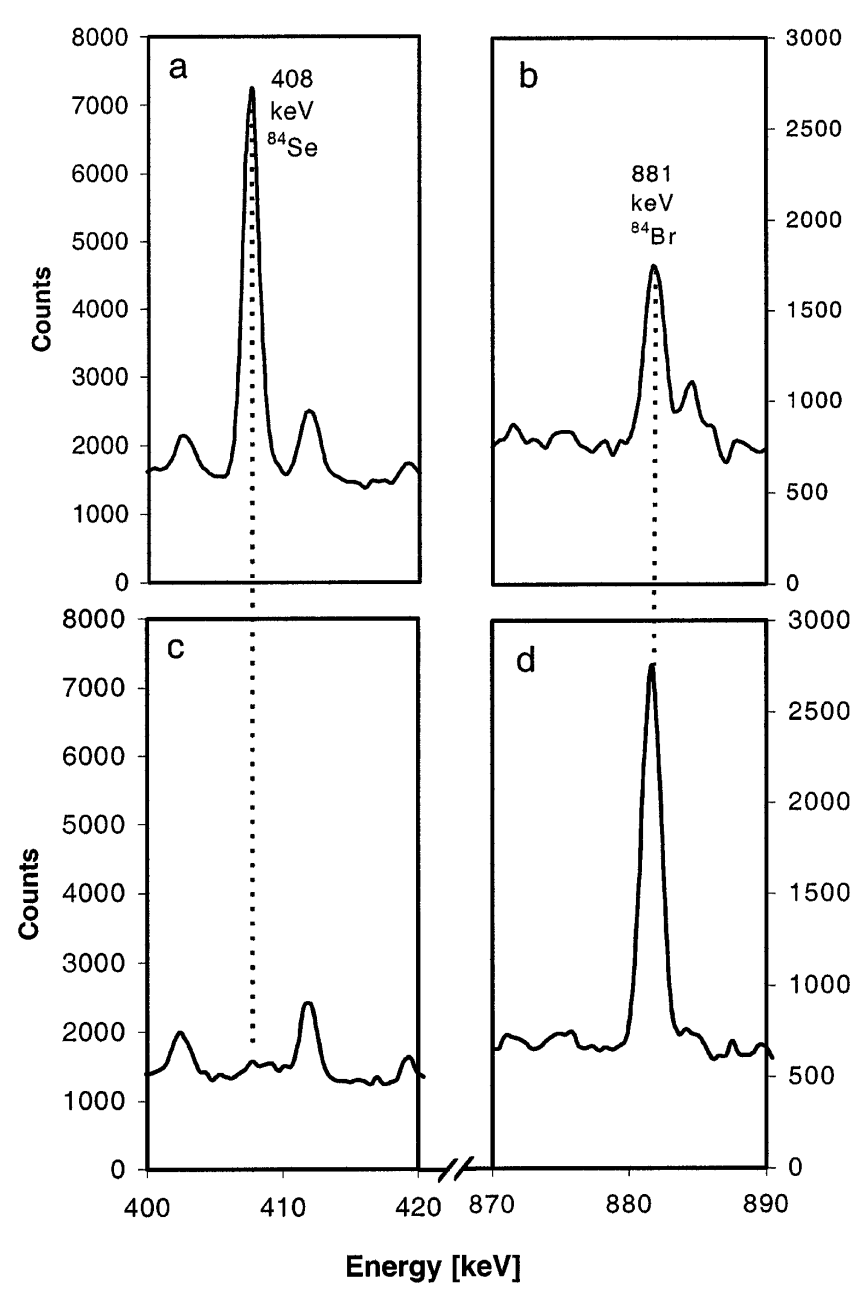

Fig. 4. Measurements of ${ }^{84} \mathrm{Se}$ and ${ }^{84} \mathrm{Br}$ in a direct catch experiment $(\mathbf{a}, \mathbf{b})$ and with addition of $500 \mathrm{ppb}$ carrier $\mathrm{Br}_{2}$ in $\mathrm{He}(\mathbf{c}, \mathbf{d})$ under tube furnace conditions like shown in Fig. 1. The trapping material was activated charcoal and the measuring time was 30 minutes each.

From the measured activities (Table 2), the transport efficiency for ${ }^{84} \mathrm{Se}$ was estimated. As a result, about $10 \%$ of all ${ }^{84} \mathrm{Se}$ atoms produced in the target chamber were detected in the laboratory, based on a fission rate of $1.0 \cdot 10^{6} \mathrm{~s}^{-1}$, a fractional cumulative yield for mass 84 of $1.005 \%$ and a neutron flux of $2.3 \cdot 10^{8} \mathrm{~s}^{-1} \mathrm{~cm}^{-2}$.

In the following, the on-line gas chemistry set-up was used to decompose OCSe and separate the daughter $\mathrm{Br}$ nuclides under three conditions: $\mathrm{CO}$ in $\mathrm{He}$ only, addition of $\mathrm{H}_{2}$ and addition of carrier $\mathrm{Br}_{2}$.

\section{Gas chemical measurements}

First, CO containing He carrier was used. No bromine carrier was added. Under these conditions, complete decomposition of the transported molecule OCSe occurred at temperatures above $800^{\circ} \mathrm{C}$ in the first tube furnace. Released Se was transported through the quartz tube at this elevated temperature and deposited on the quartz wool plug from tube furnace $2 \mathrm{kept}$ at about $200^{\circ} \mathrm{C}$ (Fig. 1). However, only poor separation of $\mathrm{Br}$ from $\mathrm{Se}$ was achieved in tube furnace 2 .

In a second step, it was checked whether addition of little hydrogen $(<5 \%)$ would increase the bromine yield, as this would favor the formation of hydrogen bromide. This resulted in an increased recovery of bromine produced in the decay of the deposited selenium. However, under these conditions still $6 \%$ of the selenium was transported to the trap, possibly due to the formation of volatile hydrogen selenide $\left(\mathrm{H}_{2} \mathrm{Se}\right)$ (Table $1 ; 3^{\text {rd }}$ line).

Finally, bromine carrier $\left(\approx 500 \mathrm{ppb} \mathrm{Br}_{2}\right)$ was added before the first tube furnace to avoid wall losses of carrierfree bromine on quartz surfaces. This carrier concentration was achieved by flowing a He gas stream over solid bromine at a temperature of $-75^{\circ} \mathrm{C}$. As a result, the bromine radionuclides could be mobilised quantitatively, most likely due to surface passivation of the quartz tube and isotope exchange to diatomic bromine (e.g. $\mathrm{Br}-{ }^{84} \mathrm{Br}$ ) [19] while retaining Se (Table $1 ; 4^{\text {th }}$ line). This latter conclusion seems to be plausible, as the transport of a single bromine atom under the described conditions is extremely unlikely. In Fig. 4 the complete separation is shown by $\gamma$-ray spectrum of an example, ${ }^{84} \mathrm{Se}\left(\mathrm{E}_{\gamma}=408 \mathrm{keV}\right)$ and its daughter ${ }^{84} \mathrm{Br}$ $\left(\mathrm{E}_{\gamma}=881 \mathrm{keV}\right)$. Shown are the measured ${ }^{84} \mathrm{Se}$ and ${ }^{84} \mathrm{Br}$ lines from the direct catch (upper part) and the corresponding lines after passing through the chemistry device at a temperature of $800^{\circ} \mathrm{C}$ of tube furnace 1 , and of tube furnace 2 of about $200^{\circ} \mathrm{C}$, respectively, and under reactive gas concentration of $600 \mathrm{ppm} \mathrm{CO}$ and $500 \mathrm{ppb} \mathrm{Br}_{2}$. The difference of the peak areas for ${ }^{84} \mathrm{Br}$ between the direct catch and the chemistry experiments is caused by slightly different counting efficiencies of the HPGe detectors at the position of the trap and the activated charcoal (see Fig. 1) as well as improved transport yield in the chemistry experiment due to carrier bromine.

Even after several hours of on-line operation, no selenium breakthrough was observed. Comparing the amount of all selenium atoms available (Fig. 2) with the measured bromine activity showed that quantitative mobilisation of bromine could be achieved.

To conclude, under the gas chemical conditions described above it was possible to develop a bromine generator via its precursor selenium. This enables the use of bromine nuclides in the synthesis of atmospherically relevant so called bromine reservoir species as for example hypobromous acid $(\mathrm{HOBr})$ or bromine nitrate $\left(\mathrm{BrONO}_{2}\right)$, which both have a high ozone depletion potential. Because of the very different half-lives of bromine nuclides from nuclear fission, a variety of time resolved experiments become possible.

Acknowledgments. The help of E. Rössler, D. Piguet, F. Arens, and U. Baltensperger is greatly appreciated. We thank the staff of the Spallation Neutron Source (SINQ) at Paul Scherrer Institute for providing stable beams during our experiments. This work was supported by the Swiss National Science Foundation.

\section{References}

1. Lary, D. J.: Gas phase atmospheric bromine photochemistry. J. Geophys. Res. 101/D1, 1505-1516 (1996).

2. Barrie, L. A., Bottenheim, J. W., Schnell, R. C., Crutzen, P. J., Rasmussen, R. A.: Ozone destruction and photochemical reactions at polar sunrise in the lower Arctic atmosphere. Nature 334, 138141 (1988).

3. Wessel, S., Aoki, S., Winkler, P., Weller, R., Herber, A., Gernandt, H.: Tropospheric ozone depletion in polar regions. A comparison 
of observations in the Arctic and Antarctic. Tellus 50B, 34-50 (1998).

4. Hebestreit, K., Stutz, J., Rosen, D., Matveiv, V., Peleg, M., Luria, M., Platt, U.: DOAS Measurements of Tropospheric Bromine Oxide in Mid-Latitudes. Science 283, 55-57 (1999).

5. Nagao, I., Matsumoto, K., Tanaka, H.: Sunrise ozone destruction found in the sub-tropical marine boundary layer. Geophys. Res. Lett. 26/22, 3377-3380 (1999).

6. Ammann, M., Kalberer, M., Jost, D. T., Tobler, L., Rössler, E., Piguet, D., Gäggeler, H. W., Baltensperger, U.: Heterogeneous production of nitrous acid on soot in polluted air masses. Nature 395, 157-160 (1998).

7. Nai-Qi, Y., Jost, D. T., Baltensperger, U., Gäggeler, H. W.: The Saphir Gas-Jet and a First Application to an On-line Separation of Niobium. Radiochim. Acta 47, 1-7 (1989)

8. Jost, D. T., Piguet, D., Frutiger, P., Pomplun, M., Fleischmann, A.: The new SINQ Gas-Jet Facility. In: Annual Report 1997, Paul Scherrer Institut, Labor für Radio- und Umweltchemie, Villigen, Switzerland (1998), p. 20.

9. Wahl, A. C.: Nuclear-charge distribution and delayed-neutron yields for thermal neutron induced fission of ${ }^{235} \mathrm{U},{ }^{233} \mathrm{U}$ and ${ }^{239} \mathrm{Pu}$ and for spontaneous fission of ${ }^{252} \mathrm{Cf}$. Atomic Data and Nuclear Data Tables 39, 1-156 (1988).

10. Kratz, K. L., Herrmann, G. : Rapid Separation of Fission Halogens by Recoil Reactions with Methane. Radiochem. Radioanal. Lett. 13/5-6, 385-390 (1973).
11. Zendel, M., Stender, E., Trautmann, N., Herrmann, G.: Chemical reactions in a gas-jet recoil-transport system: Continuous separation procedure for selenium and tellurium from fission products. Nucl. Instr. Meth. 153, 149-156 (1978).

12. Rengan, K., Lin, J., Massey, T. N., Zendel, M., Meyer, R. A.: Use of organo-metallic reactions for the isolation and study of shortlived selenium fission products and simultaneous suppression of daughter bromine activity. Radiochem. Radioanal. Lett. 50/6, 385-391 (1982).

13. Rengan, K.: Continuous gas phase chemical separations. J. Radioanal. Nucl. Chem. 142/1, 173-81 (1990).

14. Contis, E. T., Rengan, K., Griffin, H. C.: Chemical reactions of fission products with ethylene using the gas jet technique. Nucl. Instr. Meth. Phys. Res. A 353, 631-634 (1994).

15. Franck, A., Biederbick, K.: Kunststoff-Kompendium. $3^{\text {rd }}$ rev. ed., Vogel, Würzburg (1990), p. 26 and pp. 118-120.

16. Baldwin, R. S., Proto, D. O., Church, L. B.: The Formation of OCSe from the Reaction of Recoil Selenium Atoms with Carbon Monoxide. Radiochim. Acta 16, 94-96 (1971).

17. Krafft, G. A., Meinke, P. T.: Selenoaldehydes: Preparation and Dienophilic Reactivity. J. Am. Chem. Soc. 108, 1314-1315 (1986).

18. Firestone, R. B.: Table of Isotopes. $8^{\text {th }}$ ed., John Wiley \& Sons, New York (1996) (incl. update 1998).

19. Wahl, A. C., Bonner, N. A.: Radioactivity applied to Chemistry. John Wiley \& Sons, Inc., New York (1951), p. 27. 